\title{
Exercise rehabilitation for the treatment of intermittent claudication due to peripheral arterial disease of the lower extremities
}

\author{
Wilbert S. Aronow, MD, FACC, FAHA* \\ Department of Medicine, Division of Cardiology, New York Medical College, Valhalla, New York, USA
}

Lower extremity peripheral arterial disease is chronic arterial occlusive disease of the lower extremities caused by atherosclerosis. Lower extremity peripheral arterial disease may cause intermittent claudication which is pain or weakness with walking that is relieved with rest. The muscle pain or weakness after exercise occurs distal to the arterial obstruction. Since the superficial femoral and popliteal arteries are most commonly affected by atherosclerosis, the pain of intermittent claudication is most commonly localized to the calf. Atherosclerotic obstruction of the distal aorta and its bifurcation into the two iliac arteries may cause pain in the buttocks, hips, thighs, or the inferior back muscles as well as the calves.

The Rutherford classification of peripheral arterial disease includes 7 stages [1]. Peripheral arterial disease is diagnosed as stage 0 if the patient is asymptomatic, stage 1 if mild intermittent claudication is present, stage 2 if moderate intermittent claudication is present, stage 3 if severe intermittent claudication is present, stage 4 if ischemic rest pain is present, stage 5 if the patient has minor tissue loss, and stage 6 if the patient has ulceration or gangrene [1].

Patients with lower extremity peripheral arterial disease may not walk far or fast enough to induce muscle ischemic symptoms because of comorbidities such as pulmonary disease or arthritis, may have atypical symptoms unrecognized as intermittent claudication [2], may fail to mention their symptoms to their physician, or may have sufficient collateral arterial channels to tolerate their arterial obstruction. Women with lower extremity peripheral arterial disease have a higher prevalence of leg pain on exertion and at rest, poorer functioning, and greater walking impairment from leg symptoms than men with lower extremity peripheral arterial disease [3]. Poorer leg strength in women contributes to poorer lower extremity functioning in women with lower extremity peripheral arterial disease than in men with lower extremity peripheral arterial disease [3]. Women with lower extremity peripheral arterial disease develop a faster functional decline than men with lower extremity peripheral arterial disease [4]. More sedentary hours and slower outdoor walking speed are associated with faster decreases in functioning and adverse calf muscle changes in lower extremity peripheral arterial disease [5]. Increased physical activity levels during daily life are associated with less functional decline in patients with lower extremity peripheral arterial disease [6].

Exercise rehabilitation programs have been demonstrated to increase walking distance in patients with intermittent claudication due to lower extremity peripheral arterial disease through improvements in peripheral circulation, walking economy, and cardiopulmonary function $[7,8]$. The optimal exercise program for improving claudication pain distance in patients with lower extremity peripheral arterial disease uses intermittent walking to near-maximal pain during a program of at least 6 months [9]. Strength training is less effective than treadmill walking [10]. The American College of Cardiology/ American Heart Association guidelines recommend a supervised exercise program for patients with intermittent claudication due to lower extremity peripheral arterial disease [11].

Supervised exercise training is recommended for a minimum of 30-45 minutes in sessions performed at least 3 times per week for a minimum of 12 weeks and preferably for 6 months or longer [9]. Among patients with lower extremity peripheral arterial disease, self-directed walking exercise performed at least 3 times weekly is associated with significantly less functional decline during the subsequent year [12]. Exercise training improves skeletal muscle intermediary metabolism, endothelial function, and gait biomechanics in patients with lower extremity peripheral arterial disease [13]. The increased peak exercise performance after treadmill training was associated with skeletal muscle denervation [13].

A 12 week program of supervised exercise improves exercise performance and quality of life in patients with lower extremity peripheral arterial disease [10]. A supervised exercise training program is more effective than a nonstructured community walking program in improving exercise performance and quality of life in these patients [14]. Supervised exercise training programs are also associated with reduced cardiovascular mortality and reduced all-cause mortality in patients with lower extremity peripheral arterial disease $[15,16]$. On the basis of the available data, the American College of Cardiology/ American Heart Association 2013 guidelines recommend a supervised walking exercise program in patients with lower extremity peripheral arterial disease with a Class Ia recommendation and unsupervised exercise with a Class IIb recommendation [17].

Patients with intermittent claudication should be considered for revascularization to improve symptoms only in the absence of other disease that would limit exercise improvement such as angina pectoris, heart failure, chronic pulmonary disease, or orthopedic limitations

Correspondence to: Wilbert S. Aronow, MD, FACC, FAHA, Professor of Medicine, Department of Medicine, Division of Cardiology, New York Medical College, Valhalla, New York, USA, Tel: (914) 493-5311, Fax: (914)-235-6274, E-mail: wsaronow@aol.com

Received: October 31, 2016; Accepted: November 03, 2016; Published: November 04, 2016 
[11]. However, 6-month outcomes from 111 patients with claudication due to aortoiliac peripheral arterial disease randomized to optimal medical therapy, optimal medical therapy plus supervised exercise, or optimal medical therapy plus stent revascularization in the Exercise Versus Endoluminal Revascularization (CLEVER) study showed that the greatest increase in treadmill walking performance occurred in the patients randomized to optimal medical therapy plus supervised exercise [18].

The Endovascular Revascularization and Supervised Exercise (ERASE) trial randomized 212 patients with intermittent claudication due to lower extremity peripheral arterial disease to either endovascular revascularization plus supervised exercise or supervised exercise alone [19]. The follow-up duration of this study was 12 months. Endovascular revascularization plus supervised exercise improved the primary endpoint of maximum treadmill walking distance 1237 meters (from 264 meters to 101 meters), whereas supervised exercise alone improved the maximum treadmill walking distance 955 meters (from 285 meters to 1240 meters). Endovascular revascularization plus supervised exercise improved pain-free walking distance 1120 meters (from 117 meters to 1237 meters), whereas supervised exercise alone improved the maximum treadmill walking distance 712 meters (from 135 meters to 847 meters). Endovascular revascularization plus supervised exercise also improved quality-of-life scores more than did supervised exercise alone [19].

A Dutch randomized trial demonstrated that endovascular revascularization had a similar benefit but higher costs per patient than a hospital-based exercise program [20]. Another study from a Dutch database of 4,954 patients showed that a stepped approach of using supervised exercise followed by endovascular revascularization was more cost effective than endovascular revascularization alone in patients with intermittent claudication due to lower extremity peripheral arterial disease [21]. Future research studies in patients with intermittent claudication due to lower extremity peripheral arterial disease should address not only the clinical benefits of a combined program of supervised exercise plus limb revascularization but also the ability of this treatment approach to be used by appropriate patients with desired improvements in functional outcomes.

\section{Conflicts of interest}

\section{Dr. Aronow has no conflicts of interest.}

\section{References}

1. Dormandy JA, Rutherford RB (2000) TransAtlantic Inter-Society Consensus (TASC). Management of peripheral arterial disease (PAD). J Vasc Surg 31: S1-S296.

2. McDermott MM, Greenland P, Liu K, Guralnik JM, Criqui MH, et al.(2001) Leg symptoms in peripheral arterial disease. Associated clinical characteristics and functional impairment. JAMA 286: 1599-1606. [Crossref]

3. McDermott MM, Greenland P, Liu K, Criqui MH, Guralnik JM, et al. (2003) Sex differences in peripheral arterial disease: leg symptoms and physical functioning. $\mathrm{J} \mathrm{Am}$ Geriatr Soc 51: 222-228. [Crossref]

4. McDermott MM, Ferrucci L, Liu K, Guralnik JM, Tian L, et al. (2011) Women with peripheral arterial disease experience faster functional decline than men with peripheral arterial disease. J Am Coll Cardiol 57: 707-714. [Crossref]

5. McDermott MM, Liu K, Ferrucci L, Tian L, Guralnik JM, et al. (2011) Greater sedentary hours and slower walking speed outside the home predict faster declines in functioning and adverse calf muscle changes in peripheral arterial disease. $J$ Am Coll Cardiol 57: 2356-2364. [Crossref]

6. Garg PK, Liu K, Tian L, Guralnik JM, Ferrucci L, et al. (2009) Physical activity during daily life and functional decline in peripheral arterial disease. Circulation 119: 251-260. [Crossref]
7. Gardner AW, Katzel LI, Sorkin JD, Killewich LA, Ryan A, et al. (2000) Improved functional outcomes following exercise rehabilitation in patients with intermittent claudication. J Gerontol A Med Sci 55A: M570-M577. [Crossref]

8. Hamburg NM, Balady GJ (2011) Exercise rehabilitation in peripheral artery disease functional impact and mechanisms of benefits. Circulation 123: 87-97. [Crossref]

9. Gardner AW, Poehlman ET (1995) Exercise rehabilitation programs for the treatment of claudication pain. A meta-analysis. JAMA 274: 975-980. [Crossref]

10. Hiatt WR, Wolfel EE, Meier RH, Regensteiner JG (1994) Superiority of treadmill walking exercise versus strength training for patients with peripheral arterial disease. Implications for the mechanism of the training response. Circulation 90: 1866-1874. [Crossref]

11. Hirsch AT, Haskal ZJ, Hertzer NR, Bakal CW, Creager MA, et al. (2006) ACC/AHA 2005 Practice Guidelines for the management of patients with peripheral arterial disease (lower extremity, renal, mesenteric, and abdominal aortic): Executive Summary. Circulation 113: 1474-1547.

12. McDermott MM, Liu K, Ferrucci L, Criqui MH, Greenland P, et al. (2006) Physical performance in peripheral arterial disease: a slower rate of decline in patients who walk more. Ann Intern Med 144: 10-20. [Crossref]

13. Hiatt WR, Regensteiner JG, Wolfel EE, Carry MR, Brass EP (1996) Effect of exercise training on skeletal muscle histology and metabolism in peripheral arterial disease. $J$ Appl Physiol 81: 780-788. [Crossref]

14. Mays RJ, Rogers RK, Hiatt WR, Regensteiner JG (2013) Community walking programs for treatment of peripheral artery disease. J Vasc Surg 58: 1678-1687. [Crossref]

15. Chang P, Nead KT, Olin JW, Myers J, Cooke JP, et al. (2015) Effect of physical activity assessment on prognostication for peripheral artery disease and mortality. Mayo Clin Proc 90: 339-345. [Crossref]

16. Sakamoto S, Yokoyama N, Tamori Y, Akutsu K, Hashimoto H, et al. (2009) Patients with peripheral artery disease who complete 12-week supervised exercise training program show reduced cardiovascular mortality and morbidity. Circ J 73: 167-173. [Crossref]

17. Rooke TW, Hirsch AT, Misra S, Sidawy AN, Beckman JA, et al. (2013) Managemen of patients with peripheral artery disease (compilation of 2005 and $2011 \mathrm{ACCF} /$ AHA guideline recommendations): a report of the American College of Cardiology Foundation /American Heart association Task Force on Practice Guidelines. J Am Coll Cardiol 61: 1555-1570. [Crossref]

18. Murphy TP, Cutlip DE, Regensteiner JG, Mohler ER, Cohen DJ, et al. (2012) Supervised exercise versus primary stenting for claudication resulting from aortoiliac peripheral artery disease. Six-month outcomes from the Claudication: Exercise Versus Endoluminal Revascularization (CLEVER) Study. Circulation 125: 130-139. [Crossref]

19. Fakhry F, Spronk S, van der Laan L, Wever JJ, Teijink JA, et al. (2015) Endovascular revascularization and supervised exercise for peripheral artery disease and intermittent claudication: a randomized clinical trial. JAMA 314: 1936-1944. [Crossref]

20. Spronk S, Bosch JL, den Hoed PT, Veen HF, Pattynama PM, et al. (2008) Cost effectiveness of endovascular revascularization compared to supervised hospital-based exercise training in patients with intermittent claudication: a randomized controlled trial. J Vasc Surg 48: 1472-1480. [Crossref]

21. Fokkenrood HJ, Scheltinga MR, Koelemay MJ, Breek JC, Hasaart F, et al. (2014) Significant savings with a stepped care model for treatment of patients with intermittent claudication. Eur J Vasc Endovasc Surg 48: 423-429. [Crossref]

Copyright: (C)2016 Aronow WS. This is an open-access article distributed under the terms of the Creative Commons Attribution License, which permits unrestricted use, distribution, and reproduction in any medium, provided the original author and source are credited. 